\title{
UNCERTAINTIES IN NAVIGATION OF ELDERLY PEOPLE IN TOWNS - THE ASSISTANT PROJECT
}

\author{
W. Kainz ${ }^{\text {a, } *, \text { K. Kalian }}{ }^{\text {a }}$ \\ ${ }^{a}$ Department of Geography and Regional Research, University of Vienna, Universitätsstraße 7, A-1010 Vienna, Austria \\ (wolfgang.kainz, kristin.kalian)@univie.ac.at
}

KEY WORDS: public transport, elderly people, location uncertainties, PDA

\begin{abstract}
:
The ASSISTANT project contributes to maintaining the mobility of older people in Europe, in order to safeguard their social and economic participation in an increasingly ageing society. It does this by helping them to travel safely and independently by public transport. This three-year project develops an application for the home PC and smartphone that designed to help older travelers to plan their public transport journeys and then receive guidance during their journey. This guidance will help them to find the vehicle they need, warn them when to get off, when and where to change to another route, and will provide assistance if something goes wrong. There are several stages in the guidance where uncertainties play a major role and have an effect on the quality of the trip. The major uncertainty is with the location services when GPS reception in poor or impossible due to urban canyons or the user being under ground or in a tunnel. In addition, when waiting at a stop where for instance several buses might arrive at the same time, it could be difficult to identify the correct bus to board. This paper explains the overall design of the ASSISTANT project and addresses some of the issues related to positional uncertainties.
\end{abstract}

\section{INTRODUCTION}

The project Aiding SuStainable Independent Senior TrAvelers to Navigate in Towns (ASSISTANT) contributes to maintaining the mobility of older people in Europe, in order to safeguard their social and economic participation in an increasingly ageing society. It does this by helping them to travel safely and independently by public transport, and enabling them to relax and enjoy the journey whilst doing so. This three-year project develops an application for the home PC and smartphone that is designed to help older travelers to plan their public transport journeys and then receive guidance during their journey. This guidance will help them to find the means of transportation that they need, warn them when to get off, when and where to change to another route, and will also provide assistance if something goes wrong.

The main target group of the ASSISTANT project is mobile older people, particularly those travelling to unfamiliar places or beginning to use public transportation again after losing the ability to drive safely. The second user role of ASSISTANT is caregivers. In case of cognitive disabilities, the caregiver acts as a guardian and monitors the movement of the elderlies. In case of an emergency, the user can press the panic button on the smartphone and will be connected with the caregiver over the telephone.

The ASSISTANT project aids travelers in using public transportation in both rural and urban environments, and provides a simple yet effective safe route for them. ASSISTANT builds its technology on relatively familiar platforms for older people: the PC and the mobile phone. ASSISTANT provides only relevant information, at the right time and in the appropriate format, by filtering available data, and communicating with the user via audio, visual and haptic cues.

\footnotetext{
* Corresponding author.
}

ASSISTANT provides safety and security by its error trapping and remediation functionality, which makes it responsive to the user's physical, cognitive and mental capacities and preferences using the technology already available. A common problem area for users with less familiarity with computers, (not just older users), is at the intersection of two computational systems. A typical example of this is digital cameras and PCs; a successful means of saving less experienced users from having to perform complex configuration tasks is to provide a single application that provides all the functionality needed to connect the two devices. ASSISTANT ensures that both devices are easy to use, and both the interface and data transfer are seamless and transparent. The key to ASSISTANT's success is the use of well-tested and robust technologies, along with the provision of customizable user interfaces and strategies for dealing with unexpected events and their consequences. It implements reasoning functionality to handle uncertainties and to predict or anticipate the position of both users and public transportation vehicles when GPS/telematics data are missing or not reliable.

The key functions of the system are to:

- Plan an urban/interurban trip, taking into account personal accessibility needs and preferences;

- Know when to exit from the train/bus/metro/tram and, if necessary, which connection to take next;

- Get information and guidance when unexpected circumstances along a journey occur (e.g. missed a connecting bus, exited the bus at the wrong station, etc.) using a simple location and velocity based (GNSS based) error trapping system (coupled with simple multi-tiered remediation smartphone based strategies);

- Find the way home at any point during a journey.

Figure 1 shows the ASSISTANT system architecture. 


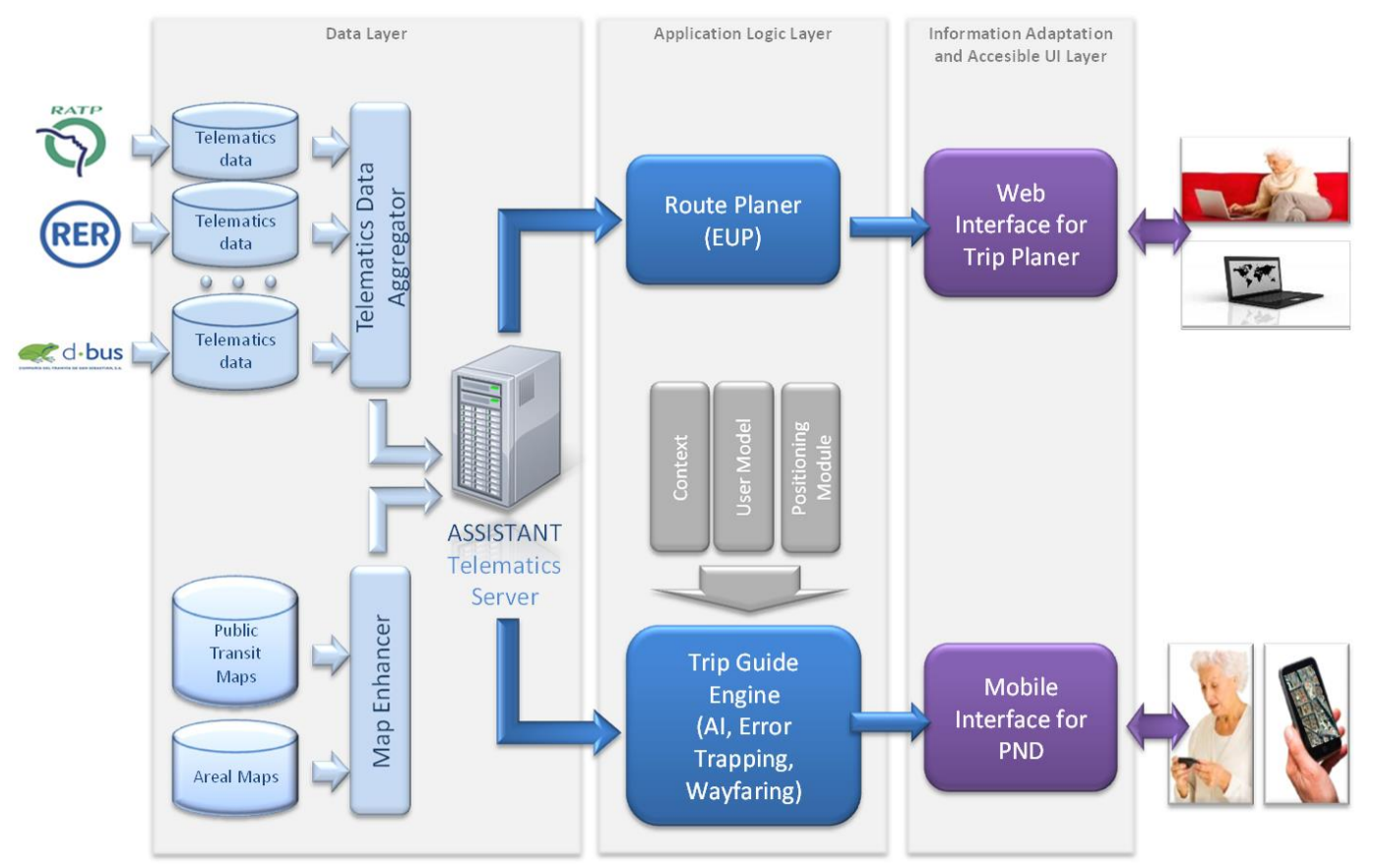

Figure 1. ASSISTANT system architecture

\section{SYSTEM DESIGN}

The system design focuses on the end-user. Therefore, an extensive user survey was conducted to learn what the needs and desires of elderly people are who use public transport (Kalian \& Kainz, 2013). This user needs analysis shapes the system and in particular, the user interfaces design. As shown in Figure 1 the system comprises three layers: data layer, application logic layer, and information adaptation and accessible user interface layer. Figure 2 shows the top-level ontology of ASSISTANT, which constitutes the skeleton of the user requirements framework.

\subsection{Data Layer}

The data layer provides all necessary data for the system, both spatial and non-spatial data. The major data sets are route network data, schedules, and other ancillary data such as reference maps and information about facilities at stations and stops (elevators, public restrooms, etc.).

\subsection{Application Logic Layer}

The application logic layer provides a route planner and a trip guide engine. The route planner will be employed when no API for local services is available. Normally, ASSISTANT will use services of local and regional transport providers to calculate the route with certain constraints defined by the user. In addition, available Open Government Data will be used as much as possible. The trip engine assists in providing error trapping and mitigation procedures that might be necessary when a traveler misses a stop or gets lost in any other way.

\subsection{Information Adaptation and Accessible User Interface Layer}

This component provides a web application where a user can plan trips from a home PC and transfer the trip to his or her mobile phone. The mobile phone app will be used for navigation of and communication with the traveler en route. In the first implementation, the app will be provided for Android phones.

ASSISTANT distinguished itself from other systems by several key assets that make navigation for elderly people easier (see Table 1).

\begin{tabular}{|c|c|}
\hline ASSISTANT & In Contrast To \\
\hline $\begin{array}{l}\text { Personalization and customi- } \\
\text { zation for accessibility needs, } \\
\text { preferences, and error } \\
\text { recovery }\end{array}$ & $\begin{array}{l}\text { One-size-fits-all; this } \\
\text { becomes especially difficult } \\
\text { in error recovery }\end{array}$ \\
\hline $\begin{array}{l}\text { Design for failure - } \\
\text { accommodating human error } \\
\text { as well as failure of system } \\
\text { components }\end{array}$ & $\begin{array}{l}\text { Making naive assumption } \\
\text { that real world use is more } \\
\text { reliable than lab use }\end{array}$ \\
\hline $\begin{array}{l}\text { Interface with the users is } \\
\text { based on HCI research and } \\
\text { using a participatory design } \\
\text { approach }\end{array}$ & $\begin{array}{l}\text { Naive design which is not } \\
\text { research based, and, more } \\
\text { specifically, not asking older } \\
\text { people what they want }\end{array}$ \\
\hline $\begin{array}{l}\text { Route planning metadata } \\
\text { includes accessibility of } \\
\text { stations, intermodal transfers, } \\
\text { and public restrooms }\end{array}$ & $\begin{array}{l}\text { Not including accessibility } \\
\text { information, thus making } \\
\text { systems more difficult, or } \\
\text { even dangerous, to use }\end{array}$ \\
\hline $\begin{array}{l}\text { Provide help for the 'last } \\
\text { kilometer' from the end of } \\
\text { the bus/train/metro trip, to } \\
\text { the final goal }\end{array}$ & $\begin{array}{l}\text { End of travel support at the } \\
\text { final station - before the } \\
\text { journey goal is reached. It is } \\
\text { often very difficult to figure } \\
\text { out how to navigate the final } \\
\text { few meters to a destination }\end{array}$ \\
\hline
\end{tabular}

Table 1. Novelty of ASSISTANT

\section{IMPLEMENTATION}

The system will be tested and deployed in three different cities: San Sebastian (Spain), Paris (France), and Vienna (Austria). 
The city of San Sebastian mainly operates bus lines, Paris has all different means of transportation, and so has Vienna. For the case of Vienna, we have access to the routing system of the local transportation authority and access to real-time location services of the vehicles is promised to be granted later this year.

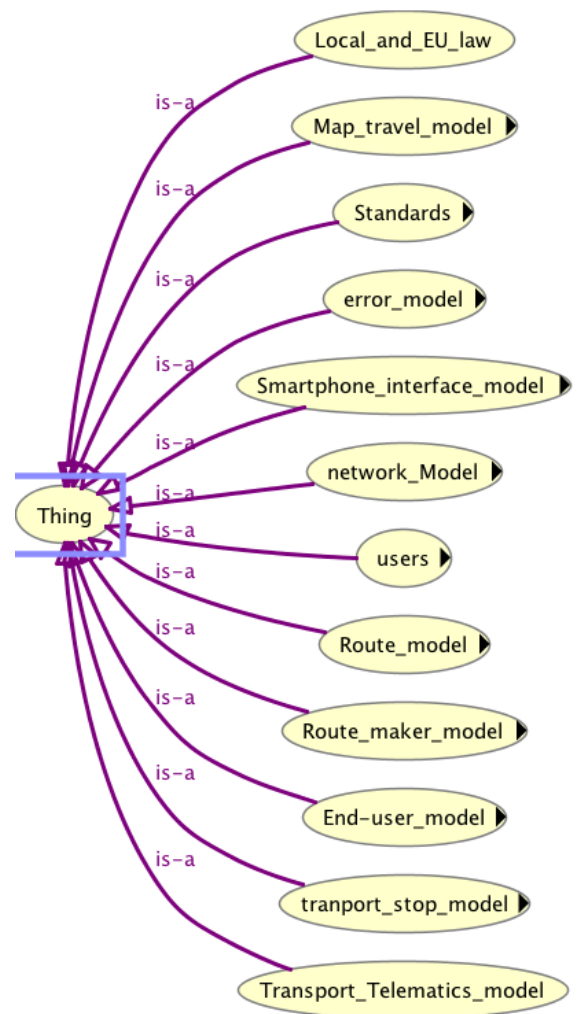

Figure 2. Top-level ontology of ASSISTANT

One of the novelties of ASSISTANT is the handling of the "last kilometer". It means that a traveler after leaving the transportation means will be guided to his/her final destination by optional ways of augmented reality, maps, or graphic and spoken directions.

The ASSISTANT iterative approach (Figure 3) contains three distinct phases: the concept phase, the pilot phase, and the prototype phase. Each phase covers a period of one year.

The concept phase is characterized by a first user requirements study and analysis. The result is the initial system design and architecture that leads to concept level developments. This consists of a set of practical tasks to perform the project's scenarios. In addition, preliminary tests in terms of a user questionnaire and recorded user observation deliver the project's architecture and tools.

The pilot phase takes into consideration the outputs of the concept phase and concept level evaluations. Furthermore, advanced tasks and interfaces based on guides and training material will be taken into account. Besides utility, the focus of this evaluation phase will be on ergonomic aspects of the pilot. After verification and validation of the user tests and questionnaires, the outputs of the pilot phase will be used again for the further phase.

The prototype phase is based on the pilot phase. The trial user acceptance test will provide valuable insights for the development of the final ASSISTANT system.

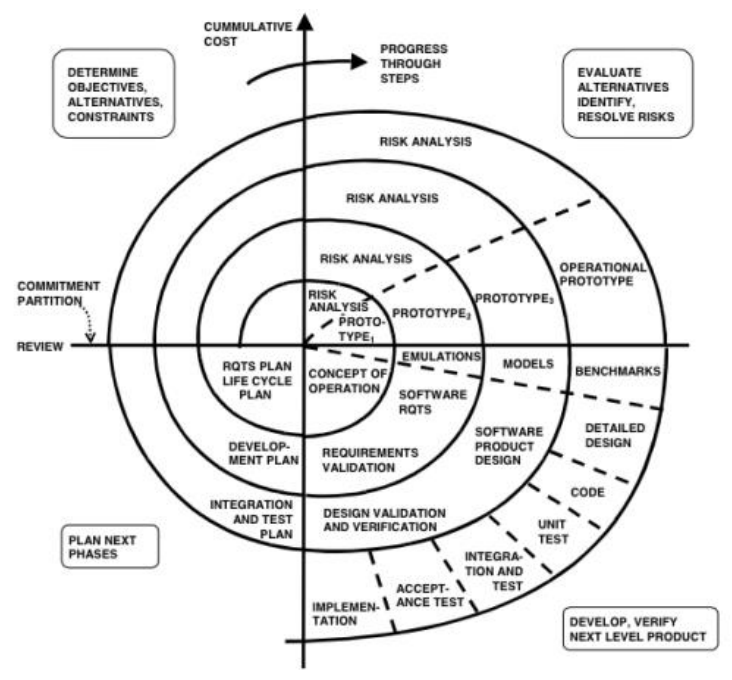

Figure 3. ASSISTANT Spiral Development Model

\section{ERROR MODEL}

ASSISTANT's error model is a first approximation of a rule based error trapping and mitigation system. In the case of this project, we circumvent the more complete approach of extracting the existence and the type of error based on user and system behavior. We expect the types of errors to be quite constrained and the amount of data to be sparse. On top of that, the capturing of errors has a high enough risk so that we have chosen to make it rule based and thus more reliable. The design of the error trapping and mitigation parts of ASSISTANT will be modular enough so that other error engines which are data driven could be inserted in place of this one.

The error model is in three parts: trapping, mitigation and an auxiliary class tree called parameters. The trapping arrangement allows, with the use of the parameters data objects, to generate error triggers, and these can be different from one user to another.

The error mitigation class will be built up as ASSISTANT user trials collect data on mitigation. There is also a decision tree support in the mitigation class, not unlike diagnosis decision trees in classical automatic medical diagnosis engines. The parameter class has a subclass named mitigation theme that supports generic types of mitigation strategies, allowing easier configuration to the individual user, and allowing tailored mitigation schemes. The error trapping and mitigation class tree will be instantiated as experience in what works and what is important is gathered in user trials. Figure 4 shows the ASSISTANT error model.

\section{SUMMARY}

ASSISTANT is an innovative project that will allow senior citizens to travel safely and comfortably in public transport. The system will take care of specific user needs and will provide help when travelers get lost (missing stop, unfamiliar environment, traffic disruptions) or meet problems in many different ways. The help will bring them back on the right line or direct them how to reach the nearest point of transfer. It will also guide them on the last part of their journey from the 
transportation means to their final destination. The project will be finished by the end of May 2015 and should reach a stage where it could be offered commercially shortly after that time.

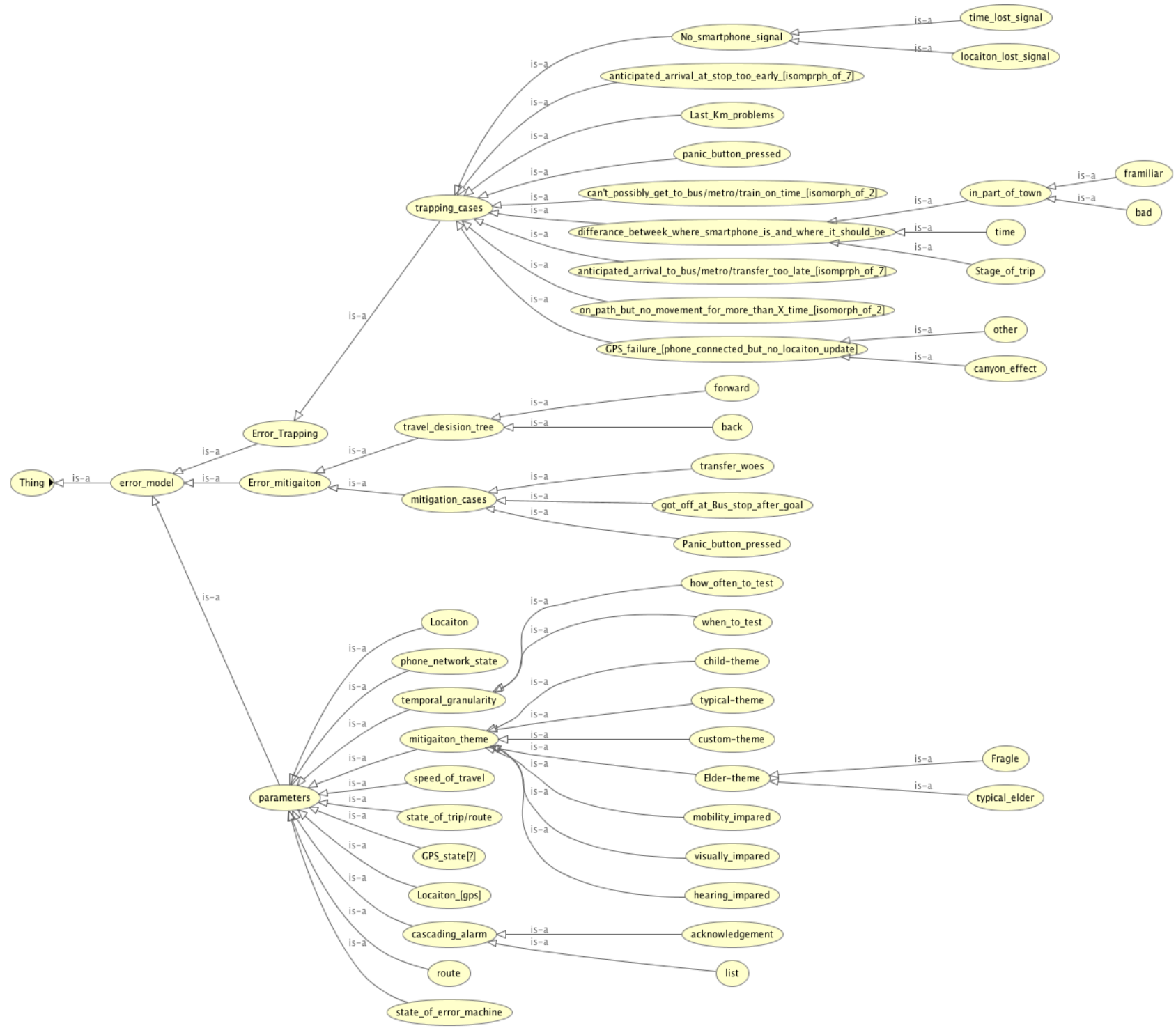

Figure 4. ASSISTANT error model

\section{REFERENCES}

AAL Joint Programme, No. AAL-2011-4-040, Proposal Part B, 2012

ASSISTANT, 2012a. D1.3 User Needs Framework. Unpublished internal project deliverable

ASSISTANT, 2012b. 'D1.4 System and Engineering Requirements. Unpublished internal project deliverable

Carmien, S., Obach, M, 2013. Back on Track: Lost and Found on Public Transportation. In: Proceedings of the $15^{\text {th }}$ International Conference on Human-Computer Interaction. 21 26 July 2013, Las Vegas, Nevada (in press).

Kalian, K., Kainz, W., 2013. ASSISTANT - Aiding Sustainable Independent Senior Travellers to Navigate in Towns. In:
Proceedings of the European Navigation Conference 2013 (in press).

\section{ACKNOWLEDGEMENTS}

ASSISTANT is part of the Ambient Assisted Living Joint Programme (AAL JP, no. AAL-2011-4-040). The three year ASSISTANT project has received funding from AAL JP, cofunded by the European Commission and national funding authorities of participant countries. The national funding agency for Austria is FFG, The Austrian Research Promoting Agency (project number 833604).

The ASSISTANT web site can be visited at the following address:

http://www.aal-assistant.eu/ 